\title{
NEURAL NETWORK IN DEVELOPING SOFTWARE FOR INDENTIFYING ARCH FORM
}

\author{
Johan Arief Budiman \\ Health Polytechnic, Ministry of Health, Indonesia
}

\begin{abstract}
The treatment of Class I malocclusion treatment is to arrange the teeth position in a good arch form. Arch form consists of tooth size and arch dimension (intercanine width, canine depth, intermolar width, molar depth). Several ways are developed to describe arch form. A lot of methods used to describe arch form qualitatively. The objective of this study is to develop qualitative arch form diagnostic references using artificial neural network from pre-post treatment dental cast scanning result. Pre-post orthodontic treatment dental casts (1990-2006) from Post Graduate Clinic Faculty of Dentistry University of Indonesia and 3 other orthodontists were gathered and scanned. Data were measured using Image Tool and analyzed using Stata 9. ANOVA was used to compare arch forms (square, oval, tapered) and gender (male and female), with each component of arch dimension upper and lower jaw, before and after treatment; and also arch perimeter to kinds of treatment The results were compiled to determine variables in building the software for analyzing arch form qualitatively. The data from 190 pre-post orthodontic treatment dental casts consisted of 42 male (22.1\%) and 148 female (77.9\%) treated without extraction $(32.63 \%), 4$ Premolars extraction (48.42\%), Upper Premolars extraction (11.05\%), atypical extraction $(7.90 \%)$. Gender and all variables from pre treatment did not influence arch form, except kinds of treatment. Therefore, only post treatment data are included for arch form analysis. The shape of arch form (square, oval and tapered) can be described qualitatively by software using artificial neural network. This software could describe arch form with the accuracy of $76.3158 \%$. This study concluded that Intercanine width, Canine depth, Intermolar width, and molar depth were variables that influenced arch form. A software using artificial neural network to describe arch form qualitatively could be used for diagnostic reference to Class I malocclusion orthodontic post treatment.
\end{abstract}

\section{Keywords:}

Artificial neural network, Arch form, Qualitative

\section{Introduction}

Malocclusion defines as any deviation from an ideal occlusion. Prevalence and severity of malocclusion varied among different ethnic groups.[1] In Indonesia malocclusion had been studied several times. Dewanto found $88.58 \%$ primary students in Lombok possessed the severity of malocclusion from light to severe.[2] In junior high school students aged 12-14 in Jakarta prevalence malocclusion was relatively high $(83.3 \%)$, varied from light to severe.[3] These showed high prevalence of malocclusion in Deuteromalayid as subject of study. 
Malocclusion classification is an important tool in deciding diagnosis and arranging comprehensive treatment plan. Angle then described these classes of malocclusion as Class I, II and III. $[4,5]$ Class I malocclusion showed normal relationship of molars, but line of occlusion was incorrect because of malposed teeth, rotation, protrusion, or other causes. The key to occlusion is that the upper and lower molars should be related so that the mesiobuccal cusp of the upper molar occludes in the buccal groove of the lower molar. Class I Canine occlusion is that upper canine cusp occludes in the contact point between lower canine and first premolar.[6,7,8]

Despite wide acceptance of the idea that arch forms vary among individuals, there is a long orthodontic tradition of seeking a single ideal arch form. Dental arches are correlated with the dimensions and the shape of the face. This variation was caused by variation in tooth size, so that it is not the goal of orthodontic treatment to produce dental arches of a single ideal size and shape for everyone.[3] Tooth size variations relate to ethnic groups and gender.[9-14]

The basic principle of arch form in orthodontic treatment is that within reason, the patient's original arch form should be preserved.[4] Most thoughtful orthodontists have assumed that this would place the teeth in a position of maximum stability. During orthodontic treatment, a lot of changes occurred within dental arches. Crowding and deformed arch form in malocclusion do not show the actual original arch forms and size, so that this condition can be changed during orthodontic treatment. At the end of the treatment, a good stability and normal function is expected.[6] A longitudinal study concerning stability of arch form was reported that when intercanine and intermolar width had been changed during orthodontic treatment, there was a strong tendency for these teeth to return to their pre-treatment position. [15]

From the literature, three basic qualitative arch forms have been repeatedly described as tapered, oval, and square. A lot of factors influence arch form such as malocclusion, Bolton's ratio,[16,17] shape of face, tooth size, habits, muscular and patient's profile.[4]

Successful orthodontic treatment is based on comprehensive diagnosis and treatment plan. Diagnosis and treatment plan arrangement based on clinical examination, cast analysis, radiograph analyzes, face and profile. The model analyzing is a time consuming procedures. Nevertheless, it is a vital part of diagnosis and subsequent treatment planning process.[18] Software to replace dental cast analysis has not been used widely. OrthoCAD [19,20] and threedimensional model analysis are rarely used in Indonesia.[20] UTHSCSA Image Tool is a free image processing and analysis program for Microsoft Windows $95^{\mathrm{TM}}$ or Windows NT ${ }^{\mathrm{TM}}$. Image Tool can acquire, display, edit, analyze, process, compress, save and print 8 and 16 gray scale and up to 24 bit color images.[21] This software can be applied to measure scanned-dental cast. Dental cast can be transformed with scanner [22] or digital camera.[23] Transformed data is analyzed applying artificial neural network. Traditionally, artificial neural network refers to a network of biological neurons. Now, it refers to a computer model of an interconnected group of artificial neurons that uses a mathematical or computational model for information processing based on a connectionist approach to computation. [24]

The objective of this research is to develop diagnostic reference for arch form qualitatively using artificial neural network from tooth size and arch dimension variables on scanned-dental cast from patients with class I malocclusion treated orthodontically. 


\section{Conceptual Framework}

The process of orthodontic diagnostic and treatment planning requires the collection of an adequate database of information about patients. Adequate information can be gathered through clinical examination, cast analysis, radiograph analysis, face and profile. Dental cast before treatment can be made by various dental plaster, such as dental stone or white orthodontic stone. From cast analysis, information about class of malocclusion, space analysis, Bolton analysis, dental arch form, curve of Spee can be gathered. With the ultimate aim of 'paperless' orthodontic office and with the already existing possibilities of the incorporating digital photos, radiograph info the electronic patient's file, the need for replacement of the plaster cast has emerged. Scanner can be used to transform dental cast without eliminating information on dental cast. Image tool can be used to measure on the scanning result

Variations in dental arches are biologic factor. During orthodontic treatment, dental arrangement and relation for upper and lower jaw would be corrected. This correction influence arch forms changes because of changing in contact point. The dental arch forms can be described qualitatively. The arch form depends on tooth size, intercanine width, intermolar width, canine depth and molar depth. Most of orthodontic softwares used Caucasoid norm are difficult to be interpreted for Indonesians. The use of artificial neural network can be apply for helping and building data bank for arch form analysis before and after orthodontic treatment. [Figure 1]

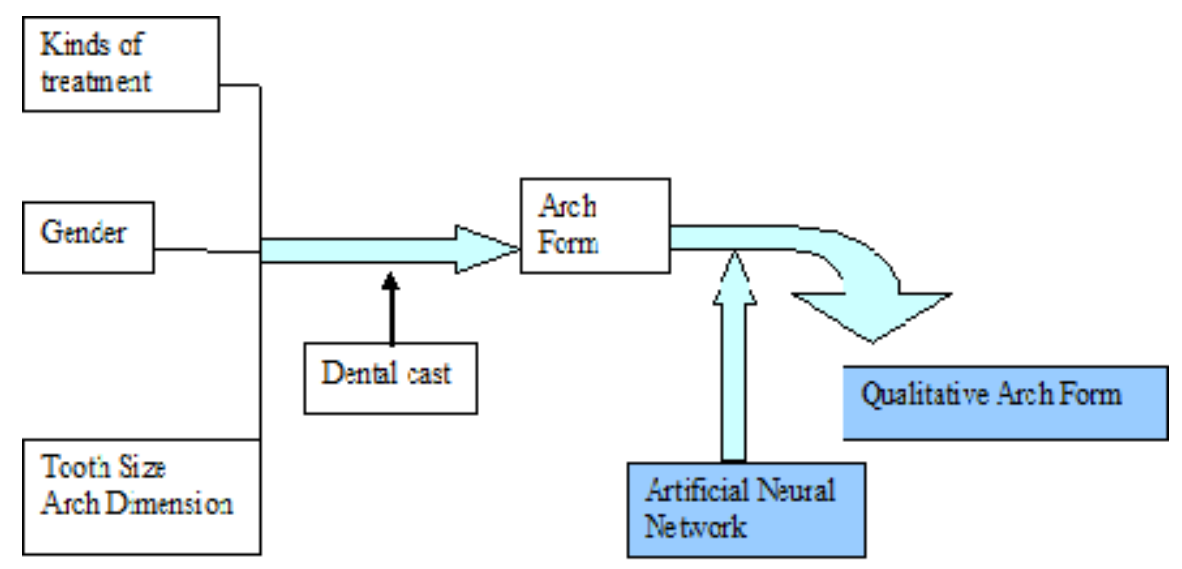

Figure 1 Conceptual Framework

\section{Major Hypothesis}

Scanned-dental cast before and after orthodontic treatment of Class I malocclusion could be used as diagnostic reference in determining arch form qualitatively using artificial neural network.

\section{Minor Hypothesis}

1. Tooth size and arch dimensions before and after orthodontic treatment of Class I malocclusion could be used as diagnostic reference in determining arch form from different gender. 
International Journal of Artificial Intelligence \& Applications (IJAIA), Vol.4, No.3, May 2013

2. The difference between tooth size and arch dimension before and after orthodontic treatment of Class I malocclusion could be used as diagnostic reference in determining arch form from different kind of treatment.

3. Tooth size and arch dimensions after orthodontic treatment of Class I malocclusion could be used as diagnostic reference in deciding arch form qualitatively using artificial neural network.

\section{Method}

This is a diagnostic research using scanned-dental cast, upper and lower, before and after orthodontic treatment of Class I malocclusion. Dental casts were gathered from Orthodontic clinic of Faculty of Dentistry, University of Indonesia and 3 other private orthodontic practices in Jakarta. Data were gathered from orthodontically treated patients from 1990-2006.

Measurement variables could be seen in Figure 2. Dependent variable was arch form and independent variables were tooth size, arch dimensions, kinds of treatment, and gender.
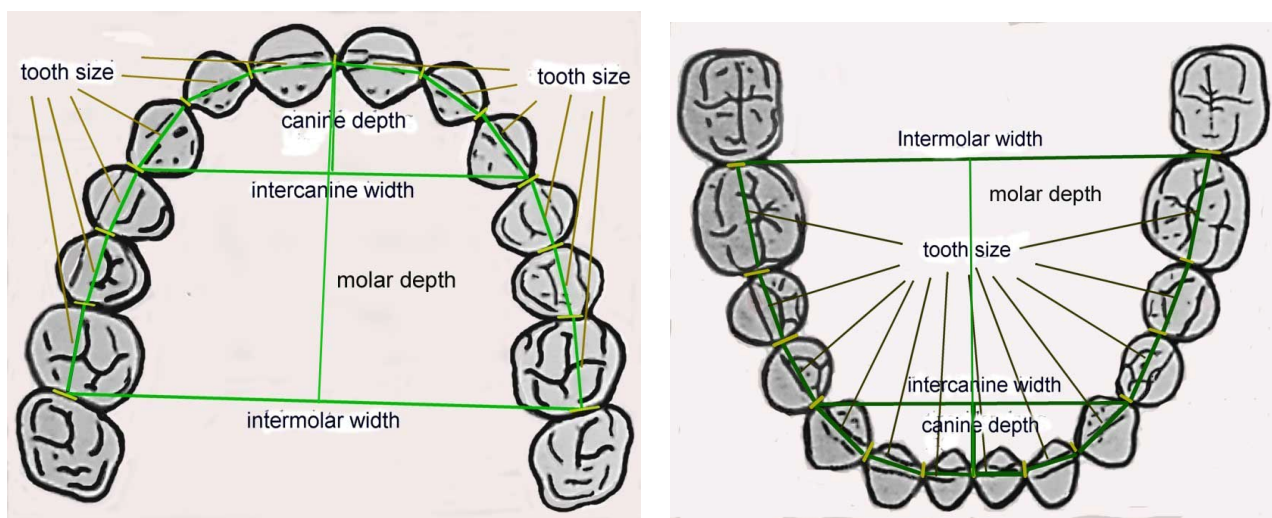

Figure 2 Dependent and Independent Measurement Variables on Scanned-dental Cast 


\section{Research Protocol}

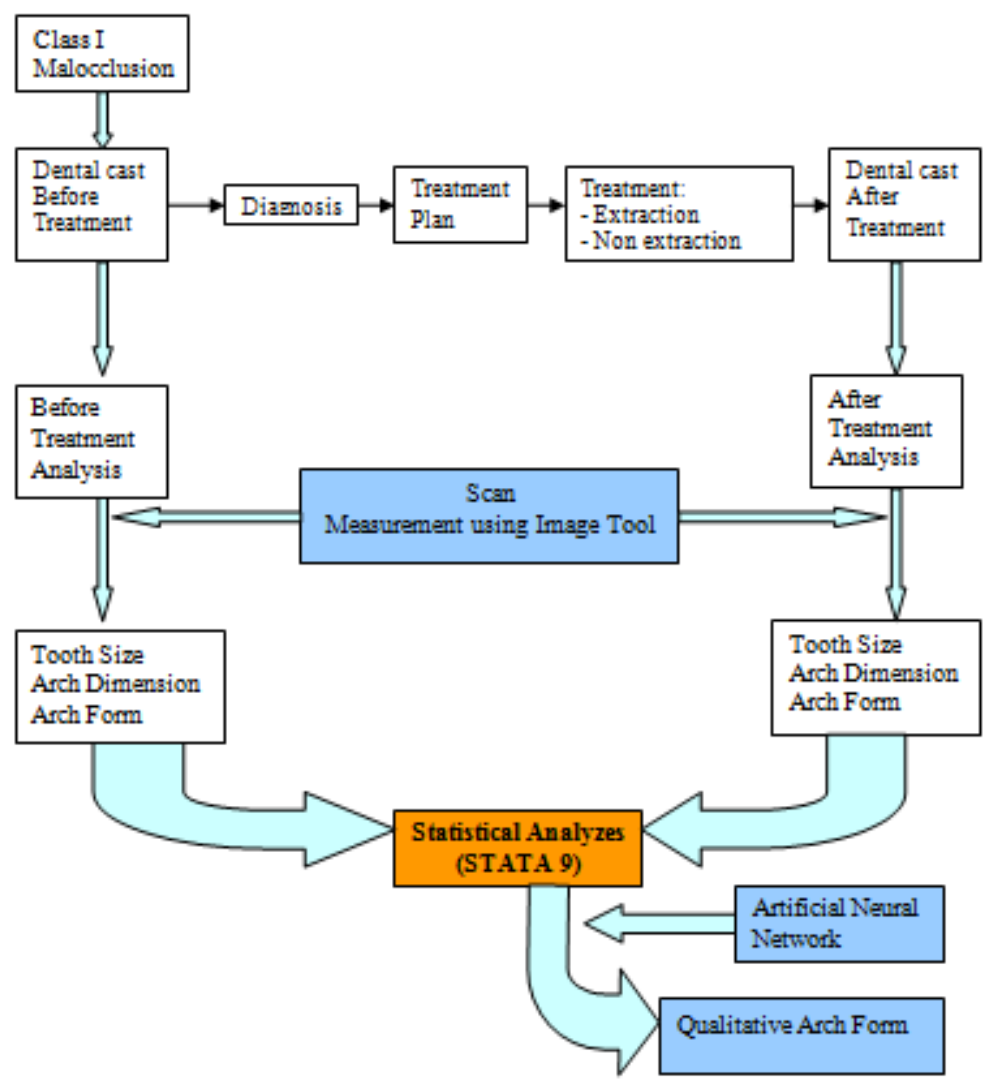

Fig.3.Research Protocol

\section{Result}

Followed the research protocol (Figure 3), one hundred and ninety pairs of dental cast before and after orthodontic treatment gathered from Orthodontic clinic of Faculty of Dentistry, University of Indonesia and 3 other private orthodontic practices in Jakarta were scanned using Microtec 5800. The dental casts originated from 42 males $(22.1 \%)$ and 148 females $(77.9 \%)$. Kinds of orthodontic treatment were as follows non extraction $(32.63 \%)$, premolars extraction $(48.42 \%)$, upper premolar extraction (11.05\%), and atypical extraction (7.90\%).

Validity of measurement was tested using variance analysis (Barlett's test and Schaffe's table) showed that there was no difference in means within and among these measurements $(p>0.05)$. Reliability of measurements before and after orthodontic treatment was tested using Bland Altman's method. The result showed that there was no significant difference on all upper and lower, before and after measurement $(\mathrm{p}>0.05)$. Normality test showed that all of the data distributed normally. 


\section{Tests of Hypothesis 1}

Tests used for proving that tooth size and arch dimensions before and after orthodontic treatment of Class I malocclusion could be used as diagnostic reference in determining arch form from different gender. Almost all of the teeth showed significant difference between male and female, except first left incisor, first left premolar, and second right premolar for the upper jaw and right canine, first left molar for the lower jaw.

ANOVA comparing arch forms (square, oval, tapered) and gender (male and female), with each component of arch dimension upper and lower jaw, before and after treatment. The results could be seen in Table 1. It indicated that there was no significant difference from all component of arch dimensions upper and lower, before and after treatment with gender $(\mathrm{p}>0.05)$

Table 1 Significances of ANOVA among Arch Form, Arch Dimensions and Gender Upper Jaw (UJ) and Lower Jaw (LJ) Before and After Orthodontic Treatment

\begin{tabular}{l|cccc}
\hline \multirow{2}{*}{ Variabel } & \multicolumn{2}{c}{ Before Treatment (n=190) } & \multicolumn{2}{c}{ After Treatment $(\mathbf{n}=\mathbf{1 9 0})$} \\
\cline { 2 - 5 } & $\mathbf{p ~ U J}$ & $\mathbf{p ~ L J}$ & $\mathbf{p ~ U J}$ & $\mathbf{p ~ L J}$ \\
\hline Gender & 0.9304 & 0.3453 & 0.5547 & 0.6993 \\
Intercanine Width & 0.8297 & 0.8219 & 0.4927 & 0.5062 \\
\hline Gender & 0.0081 & 0.6081 & 0.0216 & 0.6476 \\
Canine Depth & 0.1765 & 0.9863 & 0.1399 & 0.9778 \\
\hline Gender & 0.7794 & 0.7353 & 0.3602 & 0.7261 \\
Intermolar Width & 0.2633 & 0.8167 & 0.4871 & 0.6653 \\
\hline Gender & 0.3451 & 0.7716 & 1.0000 & 0.7891 \\
Molar Depth & 0.5664 & 0.9650 & 0.9340 & 0.1126 \\
\hline Gender & 0.4777 & 0.6556 & 0.2001 & 0.3880 \\
Anterior Perimeter & 0.2753 & 0.3239 & 0.3179 & 0.8951 \\
\hline Gender & 1.0000 & 0.4602 & 0.5471 & 0.2695 \\
Posterior Perimeter & 0.9888 & 0.9385 & 0.7471 & 0.5200 \\
\hline
\end{tabular}

Ordered logistic analysis to compare arch dimensions and gender to arch forms (square, oval, tapered) was carried out. This test was repeated until all arch dimension variables showed significant difference to arch forms, as seen in Table 2.

Table 2 Ordered Logistic Result on Arch Form with Arch Dimensions Variable using Stata 9

\begin{tabular}{|c|c|c|c|c|c|c|}
\hline Variable & coef. & S.E. & $z$ & $p$ & \multicolumn{2}{|c|}{ [95\% Conf. Interval] } \\
\hline $\mathrm{CW}$ before & 0.2192721 & 0.0603452 & 3.63 & $0.000 *$ & 0.1009977 & 0.3375466 \\
\hline CW after & -0.7006912 & 0.0877038 & -7.99 & $0.000 *$ & -0.8725876 & -0.5287949 \\
\hline $\mathrm{CD}$ after & 0.9195279 & 0.114068 & 8.06 & $0.000 *$ & 0.6959588 & 1.143097 \\
\hline MW after & 0.1476045 & 0.0517452 & 2.85 & $0.004 *$ & 0.0461857 & 0.2490232 \\
\hline MD after & -0.1517233 & 0.0377958 & -4.01 & $0.000 *$ & -0.2258017 & -0.0776449 \\
\hline
\end{tabular}




\section{Tests on Hypothesis 2}

Tests used on proving that the difference between tooth size and arch dimension before and after orthodontic treatment of Class I malocclusion could be used as diagnostic reference in determining arch form from different kind of treatment. There is no significant difference on canine depth and anterior perimeter before and after treatment $(p>0.05)$, the rest showed significant difference on before and after treatment variables $(p<0.05)$. The results of ANOVA comparing arch perimeter to kinds of treatment showed significant different among the variables $(p<0.05)$. These tests indicate that kind of treatment influence arch forms.

\section{Tests on Hypothesis 3}

Ways on describing arch forms use fundamental mathematic equations, such as parabolic shape equation. The reference parameter used for this equation were the same with reference point in this research, therefore t-test was carried out to find the significant difference between the result on this research and the result calculated by parabolic equation. There was no significant difference on anterior perimeter variables after treatment compared the result from this research and the result calculated by parabolic equation, the rest showed significant difference $(p<0.05)$. Therefore, the parabolic equation can only be used for anterior perimeter variables after treatment.

Describing arch forms qualitatively with oval, tapered and square, the data could be grouped into oval 227 casts $(59.78 \%)$, square 125 casts $(32.89 \%)$, tapered 28 casts $(7.37 \%)$. Ordered logistic analysis was performed to find out influence variables on arch forms. The results showed in Table 3.

Table 3 Ordered Logistic Analyses Result

\begin{tabular}{|c|c|c|c|c|c|c|}
\hline Variable & Coef. & S.E. & $z$ & $p$ & \multicolumn{2}{|c|}{ [95\% Conf. Interval] } \\
\hline CW after & -0.5825585 & 0.0788515 & -7.39 & $0.000 *$ & -0.7371047 & -0.4280123 \\
\hline CD after & 0.9671332 & 0.112066 & 8.63 & $0.000^{*}$ & 0.7474879 & 1.186779 \\
\hline MW after & 0.1938738 & 0.0496407 & 3.91 & $0.000 *$ & 0.0965798 & 0.2911678 \\
\hline MD after & -0.1421536 & 0.0369641 & -3.85 & $0.000 *$ & -0.2146018 & -0.0697053 \\
\hline
\end{tabular}

Notes: $*=\mathrm{p}<0.05 ; \mathrm{LR} \operatorname{chi}^{2}(4)$
Pseudo $\mathrm{R}^{2}=0.1405 ; \mathrm{n}=380$

The result of the ordered logistic was used to develop software with artificial neural network. This program used Matlab and had backpropagation learning algorithms framework. Several functions in toolbox neural Matlab were used to build this algorithm framework. This framework could be implemented to recognize arch form after doing orthodontic treatment. The artificial neural network consisted of three layers such as input layer, hidden layer and output layer. Each layer had its own activate function.

From 190 upper jaw data, $60 \%$ was used for training, and $40 \%$ for testing. Testing was carried out 20 times. Input parameters are intercanine width, canine depth, intermolar width and molar depth. Output program was the arch form, such as oval, square or tapered. Using artificial neural 
International Journal of Artificial Intelligence \& Applications (IJAIA), Vol.4, No.3, May 2013

networks to describe arch form qualitatively, the software program could identify $76.3158 \%$ of arch form correctly.

\section{Discussion}

Sampling procedure used for this research is consecutive sampling. This is a non-probability sampling. All dental casts followed sampling criteria included for this research. This is the best sampling procedure from non-probability-sampling.[24]

Dental casts of upper and lower jaw, before and after treatment was scanned using the same scanner, Microtek 5800. The best scanning result can be gained by using scanner with resolution more than 1200 dpi. $[25,26]$

Measurements was performed using Image Tool.[21] This program can be used for measuring using computer. For the calibration system, the dental casts are digitized while sitting on a sheet of millimeter graph paper in transforming by scanner.[27,28]

All data were analyzed using Stata 9 (Serial number: 1990514501). Reliability test used BlandAltman method. The plot of difference against standard measurement would show just a relation, whether there was a true association between difference and magnitude or not. The plot of difference against the average was more useful in almost all applications to medical measurements.[29-31]

Dimensional changes on arch form could be caused by arch constriction, crowding, protrusion at the beginning of the treatment. Arch expansion during orthodontic treatment might happen in extraction and non extraction treatment. Anterior segment expanded more compared to lower jaw. And lower jaw followed it as it occluded.[32] Anterior segment was presented by intercanine width and chnged due to orthodontic treatment in eliminating crowdings. Conducted in Faculty of Dentistry, University of Indonesia, previous study on intercanine width between extraction and non-extraction group found that there was a significant difference on intercanine width in extraction group compared to non-extraction group. Although statistically significance, the value of changes was still less than $1 \mathrm{~mm}$.[33]

Literature said that there was a relationship between arch changes during orthodontic treatment and stability. Relaps could occur if intercanine width expanded more than $2.5 \mathrm{~mm}$.[33] In ths study, intercanine width expanded $2.141 \mathrm{~mm}(\mathrm{p}<0.05)$ in the upper jaw and $1.479 \mathrm{~mm}(\mathrm{p}>0.05)$ in the lower jaw. Stability resulted from sample in this study should be further evaluated.

Ologit estimated ordered logistic models of ordinal variable of dependent variable on the independent variables. The actual values taken on by dependent variable were irrelevant except that larger value was assumed to correspond to 'higher' outcomes. This was a statistical technique that could sometimes be used with an ordered (from low to high) dependent variables. Ordered logistic analysis provided only one set of coefficients for each independent variable. Therefore, there was an assumption of parallel regression. That was, the coefficients for the variables in the equations would vary significantly if they were estimated separately. The intercepts would be different, but the slopes would be essentially the same. Using ordered logistic analysis, the result showed no significant difference on gender and several variables on before and after treatment measurement. This concluded that the parameters influencing arch form were intercanine width, canine depth, intermolar width and molar depth. 
The form of human dental arch described in oval, tapered and square had been used traditionally.[33,34] These variations in arch form were reflected in the arch wire. There was still a long debate on subjectivity in deciding arch form. Arch form could also be patterned using template of oval, tapered and square.[34,35] The data was analyzed using ologit command in Stata 9. In this study, there was a non equal distribution of arch form, 227 oval casts $(59.78 \%)$, 125 square casts $(32.89 \%)$, and 28 tapered casts $(7.37 \%)$.

Optimal likelihood was 92.46 with intercanine width, canine depth, intermolar width and molar depth variables giving significant difference from ordered logistic analysis with negative cut offs $(-5.2582$ and -1.3239). This concluded that intercanine width, canine depth, intermolar width and molar depth gave influence for determining arch forms.

Artificial neural networks, developed in 50's, were made up of interconnecting artificial neurons which shared some properties of biological neural networks. Artificial neural networks might either be used to gain an understanding of biological neural networks, or for solving traditional artificial intelligence tasks without necessarily attempting to model a real biological system. Artificial intelligence and cognitive modeling tried to stimulate some properties of neural networks. While similar in their techniques, the former had the aim of solving particular tasks, while the latter aimed to build mathematical models of biological neural systems, such as using physical perceptions.[36]

Traditionally, software programming was based on digital logic and could solve logical problems. The similarity between artificial neural networks and biologic neural networks could solve the problem in the same way. Artificial neural networks worked in the same manner as biologic neural networks do. Artificial neural networks could describe arch form qualitatively; the software could identify $76.3158 \%$ of arch form correctly. This number was optimum after several experiments of combining learning rate, epoch and maximum error. The rest $(23.6842 \%)$ of the data could not be recognized by the program due to overlapped distribution of the arch form data. These findings could also occur in humans. The additional dimension was needed to enhance the performance of this software program.

\section{Conclusions}

This research could conclude:

1. Some variables were significantly influencing arch form.

2. Variables in diagnostic reference influencing arch form for class I malocclusion were intercanine width, intermolar width, canine depth, and molar depth after orthodontic treatment 3. Based from the result of statistic analyses, variables for artificial neural networkscould be built. 4. Artificial neuron network to describe arch form qualitatively could identify $76.3158 \%$ of arch form correctly. 
International Journal of Artificial Intelligence \& Applications (IJAIA), Vol.4, No.3, May 2013

\section{References}

[1] Johnson JS, Soetamat A, Winoto NS, A Comparison of Some Features of Indonesian Occlusion with Those of Two Other Ethnic Groups, Brit J. Orthod, 1978; 5: 183-8.

[2] Dewanto H, Keparahan Maloklusi Siswa Sekolah Dasar di Lombok, dalam Kumpulan Naskah Ceramah Ilmiah KPPIKG VII, 1986, 136-44.

[3] Wijarnarko AG, Keparahan Maloklusi Siswa SMP usia 12-14 tahun di Jakarta, (thesis), Fakultas Kedokteran Gigi Universitas Indonesia, 1999.

[4] Proffit WR, Contemporary Orthodontics, St.Louis, The C.V. Mosby Company, 1986.

[5] Rakosi T, Jonas I, Graber TM, Color Atlas of Dental Medicine. Orthodontic-Diagnosis, New York, Thieme Medical Publisher Inc, 1993.

[6] Graber TM, Orthodontics, W.B.Saunders Company, Philadelphia, 1966, 60

[7] Idris W, Prosedur Diagnosis Kasus Ortodontik, Bagian Ortodonti FKG UI, Jakarta, 2003.

[8] Loh P, Basic Guides in Orthodontic Diagnosis, San Juan Metro Manila, Fourways Printing Inc.

[9] Black GV, Descriptive Anatomy of Human Teeth, S.S.WClicke Dental Mfg.Co., Philadelphia, Pennsylvania, 1902.

[10] Wheeler RC, A Textbook of Dental Anatomy and Physiology, W.B.Saunders, Co., Philadelphia, Pennsylvania, 1961.

[11] Bailit HL, Dental Variation among Populations: An Anthropologic View, Dental Clinics of North America, 1975; 19(1): 125-39.

[12] Bishara SE, Garcia AF, Jacobsen JR, Fahl JA, Mesiodistal Crown Dimensions in Mexico and The United States, Angle Orthod, 1986; 56: 315-23.

[13] Keene HJ, Mesiodistal Crown Diameters of Permanent Teeth in Male American Negroes, Am J Orthod, 1979; 76(1):95-9.

[14] Lavelle CLB, Maxillary and Mandibular Tooth Size in Different Racial Groups and in Different Occlusal Categories, Am J Orthod, 1972; 61: 29-37.

[15] Bishara SE, et al; Arch Width Changes from 6 Weeks to 45 Years of Age, Am J Orthod Dentofacial Orthop, 1997; 111: 401-409.

[16] Bolton WA, Disharmony in Tooth Size and Its Relation to The Analysis and Treatment of Malocclusion, Angle Orthod, 1958, 28:113-30.

[17] Bolton WA, The Clinical Application of A Tooth-size Analysis, Am J Orthod, 1962; 48: 504-29.

[18] Ranly DM, A Synopsis of Craniofacial Growth, Prentice-Hall International, Inc. 1988. p. 32-123.

[19] Zilberman O, Huggare JAV, Parikakis KA, Evaluation of the Validity of Tooth Size and Arch Width Measurements Using Conventional and Three-dimensional Virtual Orthodontic Models, Angle Orthod, 2003; 73:301-6

[20] Hayasaki H., Martins RP, Gandini Jr LG, Saitoh I, Nonaka K, A New Way of Analyzing Occlusion 3 Dimensionally, Am J Orthod Dentofacial Orthop, 2005; 128: 128-32.

[21] Wilcox D, Dove SB, McDavid WD, Greer DB, Overview UTHSCSA Image Tool, San Antonio, Texas, 1995-2002.

[22] Taner T, et al., Evaluation of Dental Arch Width and Form Changes After Orthodontic Treatment and Retention with a New Computerized Method, Am J Orthod Dentofacial Orthop 2004; 126:464-76.

[23] Sondhi A, Cleall JF, BeGole EA, Dimensional Changes in The Dental Arches of Orthodontically Treated Cases, Am J Orthod; 1980; 77(1): 60-74.

[24] Sastroasmoro S, Ismael S, Dasar-dasar Metodologi Penelitian Klinis, Sagung Seto, Jakarta, 2002.

[25] Halozonetis DJ, What Features Should I Look for in A Scanner?, Am J Orthod Dentofacial Orthop, 2004; 125: 117-8.

[26] Halozonetis DJ, At What Resolution Should I Scan Cephalometric Radiographs?, Am J Orthod Dentofacial Orthop, 2004; 125: 118-9.

[27] Paredes V, Gandia JL, Cibrian R, New, Fast, and Accurate Procedure to Calibrate a 2-Dimensional Digital Measurement Method, Am J Orthod Dentofacial Orthop. 2005; 127:518-9.

[28] Budiman JA, Soetopo MS, Perbandingan Bermacam-macam Metode Pengukuran Model Gigi, Dentika Dental Journal, 2006: 11(2). 
International Journal of Artificial Intelligence \& Applications (IJAIA), Vol.4, No.3, May 2013

[29] Altman DG, Bland JM, Measurement in Medicine: The Analysis of Method Comparison Studies, The Statistician, 1983; 32, 307-17.

[30] Bland JM, Altman DG, Statistical Methods for Acessing Agreement between Two Methods of Clinical Measurement, Lancet, 1986; I; 307-10.

[31] Bland JM, Altman DG, Comparing Methods of Measurement: Why Plotting difference against Standard Method is Misleading, Lancet, 1995; 346; 1085-87.

[32] Harlena S, Krisnawati, Purwanegara MK, Perubahan Interkaninus pada Perawatan Ortodontik, Jurnal Kedokteran Gigi UI, 2002: 9(3): 28-33.

[33] Noroozi H, Djavid GE, Moeinzad H, Teimouri AP, Prediction of Arch Perimeter Changes due to Orthodontic Treatment., Am J Orthod Dentofacial Orthop; 2002; 122: 601-7.

[34] McLaughlin RP, Bennet JC, Arch Form Considerations for Stability and Esthetics, Rev. Esp. Orthod, 1999, 29:46-63.

[35] McLaughlin RP, Bennet JC, Trevisi HJ, Systemized Orthodontic Treatment Mechanics, Mosby International Ltd, 2001, 74-91.

[36] Kusumoputro B, Jaringan Neural Buatan, Bahan Belajar Mahasiswa, Fakultas Ilmu Komputer Universitas Indonesia, 2001. 